\title{
Numerical study of mixing and heat transfer of SRF particles in a bubbling fluidized bed
}

\author{
Mohamed Sobhi Alagha ${ }^{1} \cdot$ Botond Szucs $^{1}$ (D) Pal Szentannai ${ }^{1}$
}

Received: 9 July 2019 / Accepted: 29 November 2019 / Published online: 13 December 2019

(c) The Author(s) 2019

\begin{abstract}
In this article, numerical investigations on mixing and heat transfer of solid refused fuel (SRF) particles in a bubbling fluidized bed are carried out. The numerical model is based on the Eulerian-Eulerian approach with empirical submodels representing gas-solid and solid-solid interactions. The model is verified by experimental data from the literature. The experimental data include SRF vertical distribution in SRF-sand mixtures of different sand particle sizes $\left(d_{\mathrm{pm}}=654,810\right.$ and $1110 \mu \mathrm{m})$ at different fluidization velocities $\left(u / u_{\mathrm{mf}}=1.2-2.0\right)$. We proposed magnification of drag force exerted by the gas on SRF particles based on Haider and Levenspiel (Powder Technol 58(1):63-70, 1989) drag coefficient. The proposed model shows good agreement with the experimental data at high fluidization velocities $\left(u / u_{\mathrm{mf}}=1.5-2.0\right)$ and poor predictions at low fluidization velocities $\left(u / u_{\mathrm{mf}}=1.2-1.5\right)$. Heat transfer results showed that the present model is valid and gives good agreement with the experimental data of wall-bed heat transfer coefficient.
\end{abstract}

Keywords Mixing $\cdot$ Heat transfer $\cdot$ SRF $\cdot$ Fluidized bed $\cdot$ Fluidization velocity

\section{List of symbols}

$A, B, C, D$ Coefficients (-)

$C_{\mathrm{D}} \quad$ Drag coefficient (-)

$C_{\mathrm{p}} \quad$ Particle specific heat $\left(\mathrm{J} \mathrm{kg}^{-1} \mathrm{~K}^{-1}\right)$

$d_{\mathrm{p}} \quad$ Particle diameter $(\mu \mathrm{m})$

$\varepsilon \quad$ Void fraction (-)

$g \quad$ Gravity acceleration $\left(\mathrm{ms}^{-2}\right)$

$h \quad$ Heat transfer coefficient $\left(\mathrm{Wm}^{-2} \mathrm{~K}^{-1}\right)$

$K_{\mathrm{gs}} \quad$ Momentum exchange coefficient $\left(\mathrm{kgm}^{-3} \mathrm{~s}^{-1}\right)$

$\lambda$ Thermal conductivity $\left(\mathrm{Wm}^{-1} \mathrm{~K}^{-1}\right)$

$\mu \quad$ Viscosity (Pas)

$\mathrm{Nu} \quad$ Nusselt number $=\frac{h d_{\mathrm{p}}}{\mu \mathrm{C}_{\mathrm{T}}}(-)$

Pr Prandtl number $=\frac{\mu \mathcal{c}_{\mathrm{p}}}{\lambda}(-)$

$\rho \quad$ Density $\left(\mathrm{kgm}^{-3}\right)$

$\mathrm{Re} \quad$ Reynolds number $=\frac{\rho_{\mathrm{g}} d_{\mathrm{p}}\left|u_{\mathrm{g}}-u_{\mathrm{p}}\right|}{\mu_{\mathrm{g}}}(-)$

$T \quad$ Temperature $\left({ }^{\circ} \mathrm{C}\right)$

Botond Szucs

szucsbotond@energia.bme.hu

Mohamed Sobhi Alagha

alagha@energia.bme.hu

Pal Szentannai

szentannai@energia.bme.hu

1 Department of Energy Engineering, Faculty of Mechanical Engineering, Budapest University of Technology and Economics (BME), Budapest, Hungary

\begin{tabular}{|c|c|}
\hline$u$ & Velocity $\left(\mathrm{ms}^{-1}\right)$ \\
\hline$\psi$ & Particle shape factor $(-)$ \\
\hline \multicolumn{2}{|c|}{ Subscripts and superscripts } \\
\hline $\mathrm{D}$ & Drag \\
\hline$g$ & Gas \\
\hline $\mathrm{m}$ & Mean \\
\hline $\mathrm{m}$ & Minimum fluidization \\
\hline $\mathrm{p}$ & Particle \\
\hline & Solid \\
\hline
\end{tabular}

\section{Introduction}

Fluidized beds offer excellent mixing and heat transfer characteristics which make them efficient in thermal conversion applications, i.e., combustion/gasification of low-grade coal, biomass, and solid refused fuel (SRF) [38]. Practically, fuel particles are of irregular shapes and they enter the fluidized bed at a size range of 5-10 $\mathrm{mm}$ [27]. The overall fuel concentration within the fluidized bed combustor is very low compared to the bed material (2-5 mass\%) [27]; however, the big differences in the density and size ratios can significantly affect the homogeneity of the bed (segregation phenomenon) [32]. In general, the segregation occurs during fluidization of binary beds containing two or more solid components of different sizes and/or densities. The heavier 
particles (jetsam) tend to settle down to the bottom of the bed, while the lighter particles (flotsam) float to the upper layers of the bed [26]. This heterogeneous phenomenon can have significant consequences on other processes such as heat transfer, mass transfer, and chemical reactions [30, 33]. Thus, many studies have been concerned with the segregation phenomenon of the binary fluidized bed in both the bubbling $[6,9,10,19,29]$ and the circulating fluidized beds $[28,49,51]$. Most of the binary fluidized bed studies were concentrating on moderate particle sizes of Geldart B class [11], while few of them studied large particles of Geldart D class [11].

The binary mixture Geldart B-D which is relevant to the fluidized bed combustors did not get enough interest. In the meantime, the particles of the bed material and the fuel material are of non-spherical, irregular shape in addition to the heterogeneous physical properties of some fuel materials such as solid refused fuel (SRF) and municipal solid waste (MSW). A considerable number of experimental and theoretical studies were performed to investigate hydrodynamics and combustion/gasification of SRF/MSW [4, 5, 7, 20, 22-25, 31, 36, 39, 43-45, 47], but few studies have been concerned with simulation of this complex binary mixtures (irregular shape and large size) particles in fuel-sand bubbling fluidized beds [41, 42]. Although, some trials have been performed to simulate the non-spherical particles [15, $18,46,50]$, in fact, the shape of SRF particles cannot be treated as regular particles (see Fig. 1).

The objective of the present study is to shed the light on mixing and heat transfer of this heterogeneous binary mixture of SRF-sand. The Eulerian-Eulerian multi-fluid model (MFM) is used to simulate the segregation of the fuel particles (SRF) at different fluidization velocities. Three gas-solid drag models of Gidaspow [13]. Syamlal-O'Brien [40], and Gibilaro et al. [12] are compared. Because of the heterogeneity of SRF particles, the numerical simulations are performed on representative particles of average density and sizes, but with taking into account effect of irregular-shaped large particles (sphericity ratio) on gas-solid

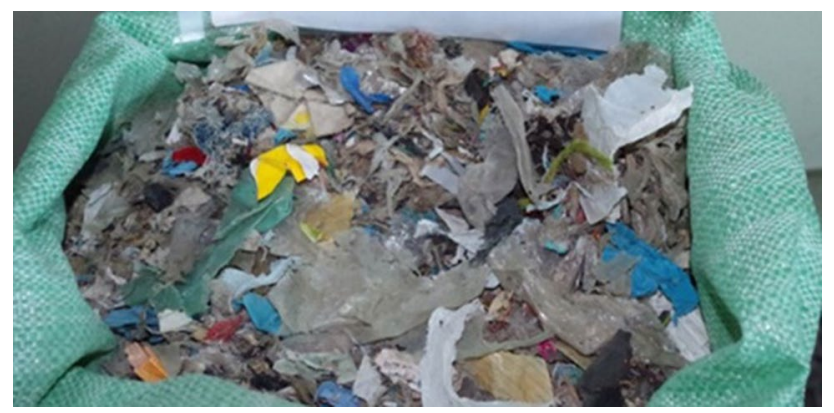

Figure 1 A photograph showing heterogeneity of solid refused fuel (SRF) momentum interaction. The heat transfer between gas and solid phases is simulated using the Gunn [16] model.

\section{Computational model}

The computational model used in the present study is based on the Eulerian-Eulerian approach in which gas and solid phases are treated as a continuum. This multi-fluid model is proposed in the present study simulations because of its fast computation compared to the other multiphase models. Also, the MFM proved reliability in fluidized bed simulations.

\section{Governing equations}

The governing equations of fluid flow are applied to both gas and solid phases as in [1] as shown in Table 1:

\section{Gas-solid drag model}

The gas-solid drag model is the inherent part of fluidization modeling as it represents the momentum exchange between the gas (fluidization agent) and the solids (the bed particles). In the present study, we are comparing the performance of the top commonly used drag models: the Gidaspow [13] model and the Syamlal-O'Brien [40] model, in addition to the Gibilaro et al. [12] model. The term $K_{\mathrm{gs}}$ in the gas and solids momentum conservation equations (Table 1 ) is the gas-solid momentum exchange. The major force causing momentum interaction is drag force which can be estimated from the empirical drag closures as follows:

Table 1 Governing equations of the present model

Continuity equation of the $q$ th phase

$\frac{\partial\left(\varepsilon_{\mathrm{q}} \rho_{\mathrm{q}}\right)}{\partial t}+\nabla \cdot\left(\varepsilon_{\mathrm{q}} \rho_{\mathrm{q}} U\right)=0$

Momentum equation of the $q$ th phase

$\frac{\partial\left(\varepsilon_{\mathrm{q}} \rho_{\mathrm{q}} U_{\mathrm{q}}\right)}{\partial t}+\nabla \cdot\left(\varepsilon_{\mathrm{q}} \rho_{\mathrm{q}} U_{\mathrm{q}} U_{\mathrm{q}}\right)=-\varepsilon_{\mathrm{q}} \cdot \nabla p-\nabla \cdot \overline{\overline{\tau_{\mathrm{q}}}}+\varepsilon_{\mathrm{q}} \rho_{\mathrm{q}} g$
$\quad+\left(\delta_{\mathrm{qs}} I_{\mathrm{gs}}-\delta_{\mathrm{qg}} I_{\mathrm{gs}}\right)+\delta_{\mathrm{ik}} \zeta_{\mathrm{ik}}\left(U_{\mathrm{sk}}-U_{\mathrm{si}}\right)$

Energy equation of the $q$ th phase

$\frac{\partial\left(\varepsilon_{\mathrm{q}} \rho_{\mathrm{q}} H_{\mathrm{q}}\right)}{\partial t}+\nabla \cdot\left(\varepsilon_{\mathrm{q}} \rho_{\mathrm{q}} U_{\mathrm{q}} H_{\mathrm{q}}\right)=\nabla \cdot\left(\varepsilon_{\mathrm{q}} \lambda_{\mathrm{q}} \nabla \cdot T_{\mathrm{q}}\right)+\left(\delta_{\mathrm{qs}} J_{\mathrm{gs}}-\delta_{\mathrm{qg}} J_{\mathrm{gs}}\right)$

$\delta_{\mathrm{qi}}=1$ if $q=i, \delta_{\mathrm{qi}}=0$ if $q \neq i$

Stress tensor of the gas phase

$\overline{\overline{\tau_{\mathrm{g}}}}=\varepsilon_{\mathrm{g}} \mu_{\mathrm{g}}\left[\nabla U_{\mathrm{g}}+\nabla U_{\mathrm{g}}^{\mathrm{T}}-\frac{2}{3}\left(\nabla \cdot U_{\mathrm{g}}\right) \overline{\bar{I}}\right]$

Stress tensor of the solid phase

$\overline{\overline{\tau_{\mathrm{s}}}}=\left(-p_{s}+\varepsilon_{\mathrm{s}} \mu_{b, s} \nabla \cdot U_{s}\right) \overline{\bar{I}}+\varepsilon_{\mathrm{s}} \mu_{\mathrm{s}}\left[\nabla U_{s}+\nabla U_{s}^{\mathrm{T}}-\frac{2}{3}\left(\nabla \cdot U_{s}\right) \overline{\bar{I}}\right]$

$\mu_{\mathrm{s}}=\mu_{\mathrm{s}, \mathrm{col}}+\mu_{\mathrm{s}, \mathrm{kin}}+\mu_{\mathrm{s}, \mathrm{fr}}$

$\mu_{\mathrm{s}, \mathrm{kin}}=\frac{10 \rho_{\mathrm{s}} d_{\mathrm{p}} \sqrt{\Theta_{\mathrm{s}} \pi}}{96 \varepsilon_{\mathrm{s}}\left(1+e_{\mathrm{ik}}\right) g_{\mathrm{ik}}}\left[1+\frac{4}{5} g_{\mathrm{ik}} \varepsilon_{\mathrm{s}}\left(1+e_{\mathrm{ik}}\right)\right]$

$\mu_{\mathrm{s}, \mathrm{col}}=\frac{4}{5} g_{\mathrm{ik}} \varepsilon_{\mathrm{s}} \rho_{\mathrm{s}}\left(1+e_{\mathrm{ik}}\right) \sqrt{\Theta_{\mathrm{s}} / \pi}$

$\mu_{\mathrm{s}, \mathrm{fr}}=\frac{p_{\mathrm{s}} \sin \theta_{\mathrm{i}}}{2 \sqrt{I_{2} D}}$ 
- Gidaspow [13] model

$K_{\mathrm{gs}}= \begin{cases}150 \frac{\varepsilon_{\mathrm{s}}\left(1-\varepsilon_{\mathrm{g}}\right) \mu_{\mathrm{g}}}{\varepsilon_{\mathrm{g}} d_{\mathrm{p}}^{2}}+1.75 \frac{\rho_{\mathrm{g}} \varepsilon_{\mathrm{s}}\left|u_{\mathrm{g}}-u_{\mathrm{p}}\right|}{d_{\mathrm{p}}}, & \text { for } \varepsilon_{\mathrm{g}} \leq 0.8 \\ \frac{3}{4} C_{\mathrm{D}} \frac{\varepsilon_{\mathrm{g}} \varepsilon_{\mathrm{g}} \rho_{\mathrm{g}}\left|u_{\mathrm{g}}-u_{\mathrm{p}}\right|}{d_{\mathrm{p}}} \varepsilon_{\mathrm{g}}^{-2.65}, & \text { for } \varepsilon_{\mathrm{g}}>0.8\end{cases}$

where $C_{\mathrm{D}}$ is the drag coefficient of a single sphere and is given as in [35] as follows:

$C_{\mathrm{D}}= \begin{cases}\frac{24}{\varepsilon_{\mathrm{g}} \mathrm{Re}_{\mathrm{p}}}\left[1+0.15\left(\varepsilon_{\mathrm{g}} \operatorname{Re}_{\mathrm{p}}\right)^{0.687}\right], & \text { for } \mathrm{Re}_{\mathrm{p}} \leq 1000 \\ 0.44, & \text { for } \operatorname{Re}_{\mathrm{p}}>1000\end{cases}$

where $\operatorname{Re}_{\mathrm{p}}=\frac{\rho_{\mathrm{g}}\left|u_{\mathrm{p}}-u_{\mathrm{g}}\right| d_{\mathrm{p}}}{\mu_{\mathrm{g}}}$

- Syamlal-O’Brien [40] model

$K_{\mathrm{gs}}=\frac{3}{4} \frac{C_{\mathrm{D}} \operatorname{Re}_{\mathrm{p}}}{v_{\mathrm{r}, \mathrm{s}}^{3}} \frac{\varepsilon_{\mathrm{s}} \rho_{\mathrm{g}}\left|u_{\mathrm{g}}-u_{\mathrm{p}}\right|}{d_{\mathrm{p}}}$

where

$$
\begin{aligned}
& C_{\mathrm{D}}\left(\operatorname{Re}_{\mathrm{p}}\right)=\left[0.63+\frac{4.80}{\sqrt{\operatorname{Re}_{\mathrm{p}} / v_{\mathrm{r}, \mathrm{s}}}}\right]^{2} \\
& v_{\mathrm{r}, \mathrm{s}}=0.5\left[A-0.06 \operatorname{Re}_{\mathrm{p}}\right. \\
& \left.\quad+\sqrt{\left(0.06 \operatorname{Re}_{\mathrm{p}}\right)^{2}+0.12 \operatorname{Re}_{\mathrm{p}}(2 B-A)+A^{2}}\right]
\end{aligned}
$$

$$
A=\varepsilon_{\mathrm{g}}^{4.14}, B= \begin{cases}0.8 \varepsilon_{\mathrm{g}}^{1.28}, & \text { for } \varepsilon_{\mathrm{g}} \leq 0.85 \\ \varepsilon_{\mathrm{g}}^{2.65}, & \text { for } \varepsilon_{\mathrm{g}}>0.85\end{cases}
$$

- Gibilaro et al. [12] model

$$
K_{\mathrm{gs}}=\left[\frac{17.3}{\mathrm{Re}_{\mathrm{p}}}+0.336\right] \frac{\rho_{\mathrm{g}}\left|u_{\mathrm{g}}-u_{\mathrm{p}}\right|}{d_{\mathrm{p}}} \varepsilon_{\mathrm{s}} \varepsilon_{\mathrm{g}}^{-1.8}
$$

Figure 2 shows a comparison among drag models used in the present study at different voidage and Reynolds numbers. The Syamlal-O'Brien model has the highest drag force values, while the Gibilaro et al. model shows relatively lower drag than the Gidaspow model.

\section{Effect of particles' sphericity on gas-solid drag}

SRF particles have irregular shapes; in order to simplify the modeling of such a complex system, we proposed studying SRF particles overall sphericity ratio on the prediction accuracy. Two non-spherical drag coefficient models were compared, namely the Haider and Levenspiel [17] model and the Dioguardi et al. [8] model given by the following equations:
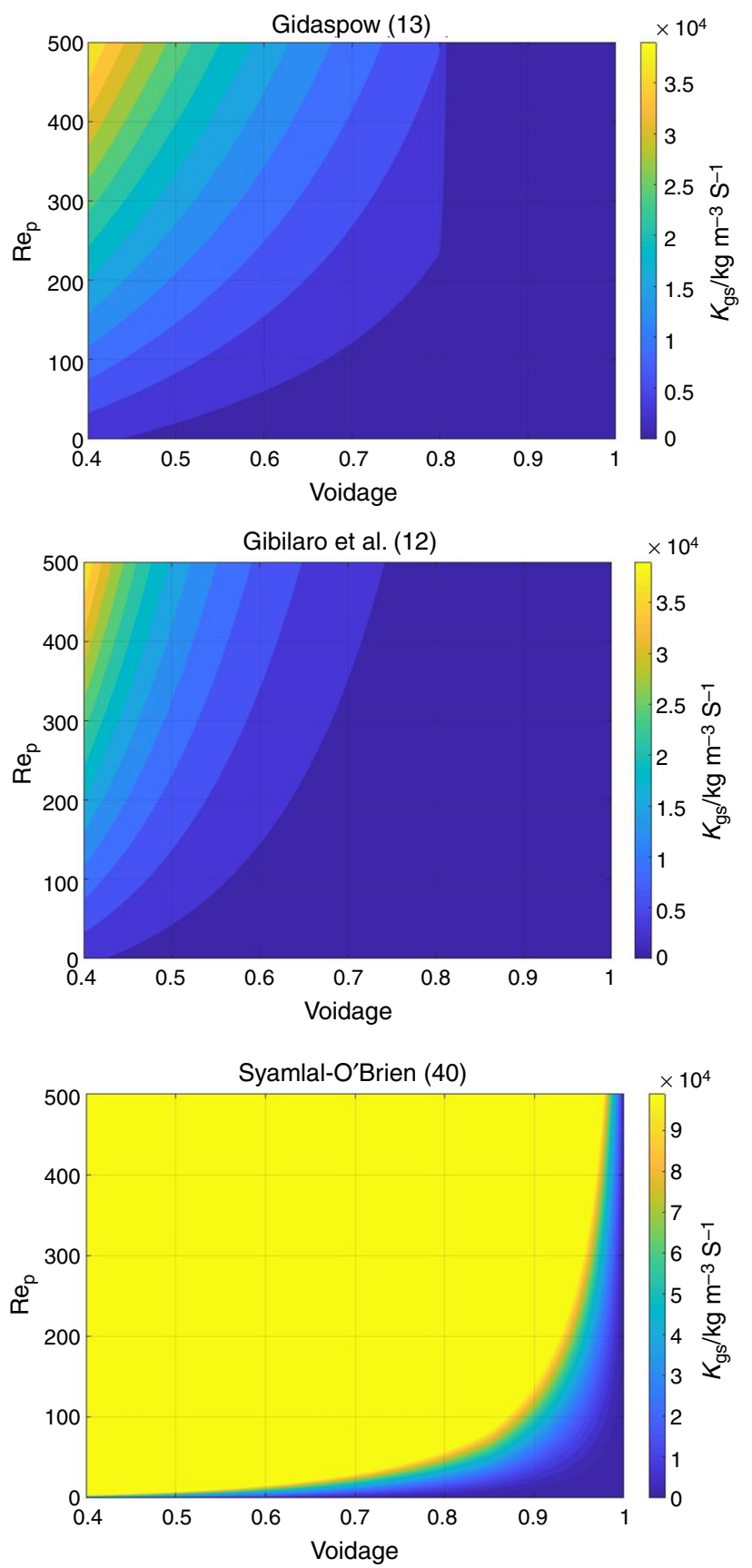

Figure 2 A comparison among the Gidaspow [13], the Gibilaro et al. [12], and the Syamlal-O'Brien [40] drag models at different voidage and Reynolds numbers

Haider and Levenspiel [17] drag coefficient

$C_{\mathrm{D}}=\frac{24}{\operatorname{Re}_{\mathrm{p}}}\left[1+A \mathrm{Re}_{\mathrm{p}}^{\mathrm{B}}\right]+\frac{C}{1+\frac{D}{\operatorname{Re}_{\mathrm{p}}}}$ 
Dioguardi et al. [8] drag coefficient

$$
\begin{aligned}
C_{\mathrm{D}}= & \frac{24}{\operatorname{Re}_{\mathrm{p}}}\left[\frac{1-\psi}{\operatorname{Re}_{\mathrm{p}}}+1\right]^{0.25} \\
& +\frac{24}{\operatorname{Re}_{\mathrm{p}}}\left[0.1806 \mathrm{Re}_{\mathrm{p}}^{0.6459}\right] \psi^{-\operatorname{Re}_{\mathrm{p}}^{0.08}}+\frac{0.4251}{1+\frac{6880.95}{\operatorname{Re}_{\mathrm{p}}} \psi^{-5.05}}
\end{aligned}
$$

where $A, B, C$, and $D$ are fitting coefficients which depend on particle sphericity ratio, while $\psi$ is the shape factor which is the ratio of particle's sphericity to circularity.

We implemented user-defined functions (UDFs) in ANSYS Fluent R18.2 solver to include particles sphericity modification on gas-solid drag force calculations as shown in Fig. 3. This figure indicates the variation on Gidaspow drag force calculated using different sphericity ratio drag coefficients. It is obvious the increase in the drag force due to the decrease in the sphericity ratio.

\section{Simulation method}

The finite volume method is used to convert the fluid flow governing equations of both gas and solids phases into linear algebraic numerical equations. The discretized equations are solved by the commercial CFD code ANSYS Fluent R18.2. The 2D fluidized bed is constructed and meshed using ANSYS Design modeler and ANSYS ICEM subprograms, respectively. While, the results are post-processed using ANSYS CFD Post and MATLAB R2017a. The mesh size is set in the range below 10 times the particle size which was found sufficient to achieve good accuracy [2]. Figure 4 represents a schematic of dimensions and boundary conditions applied in the present model.

The bed is initially well mixed with 0.86 mass\% SRF overall concentration. The no-slip and partial-slip wall boundary conditions are assigned to gas and solid, respectively. The specularity factor is set to 0.6 , while particle-wall restitution coefficient is set to 0.9 . A summary of simulation parameters and numerical variables used in the present simulations is listed in Table 2.

\section{Results and discussion}

\section{Model validation}

\section{Spherical Geldart D systems}

Literature studies reported that the gas-solid drag model is the most significant element in modeling of binary fluidized beds $[3,49,51]$. Moreover, the Gidaspow model showed good validation in the case of Geldart B binary systems. But, there are no sufficient validation studies regarding Geldart

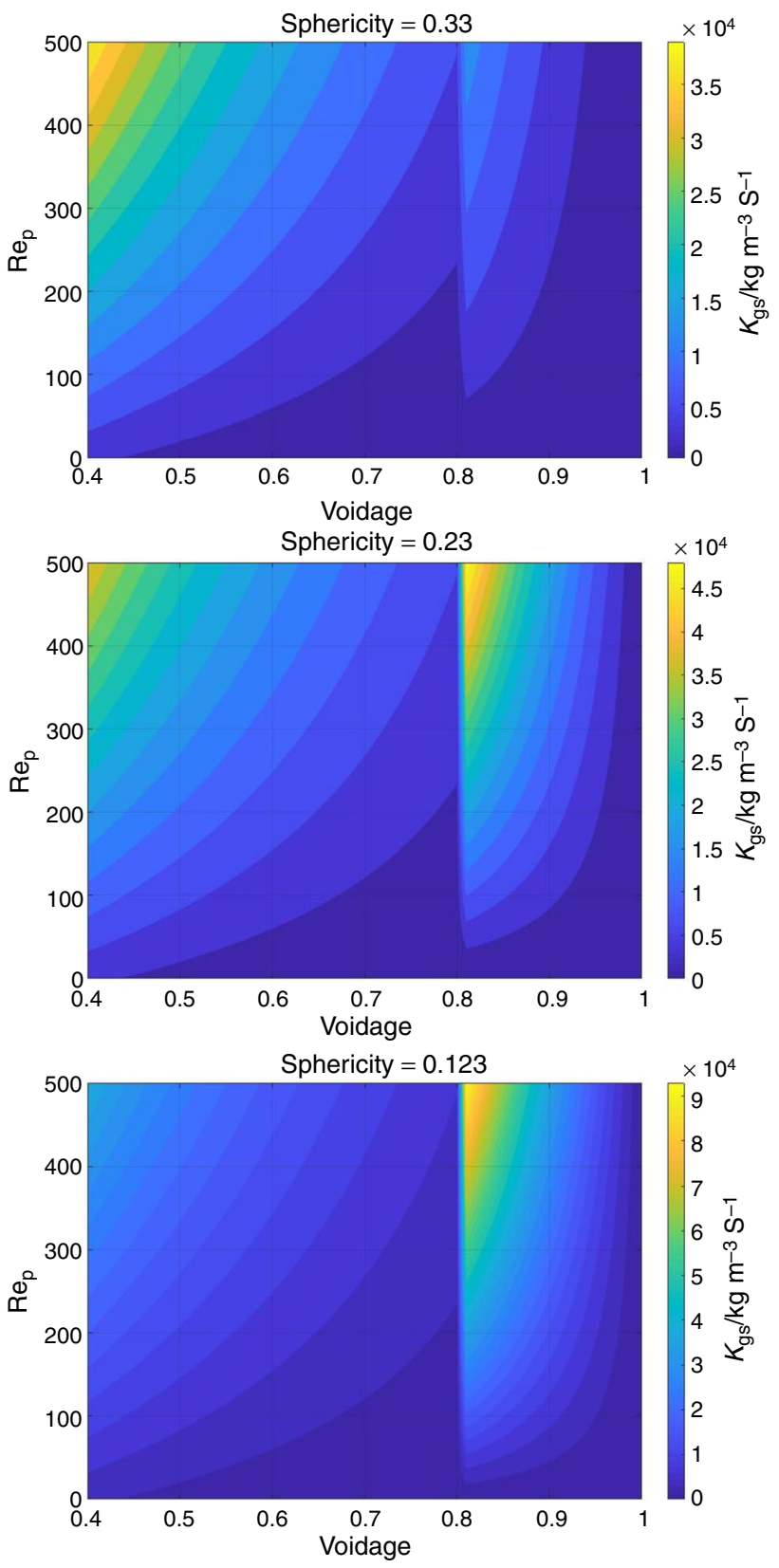

Figure 3 Effect of particles' sphericity on gas-solid drag force using Gidaspow model

D binary systems. Thus, we chose Geldart D binary systems from the literature for preliminary validation. Figure 5 shows jetsam concentration profiles predicted using different drag models in comparison with experimental data from the literature of Geldart D binary system. The results showed that the Gidaspow and the Syamlal-O'Brien models can give overall good agreement with the experimental data of Geldart D systems of different density ratios. The Gibilaro et al. model cannot give reliable predictions that qualify it to the next phase of model testing. 


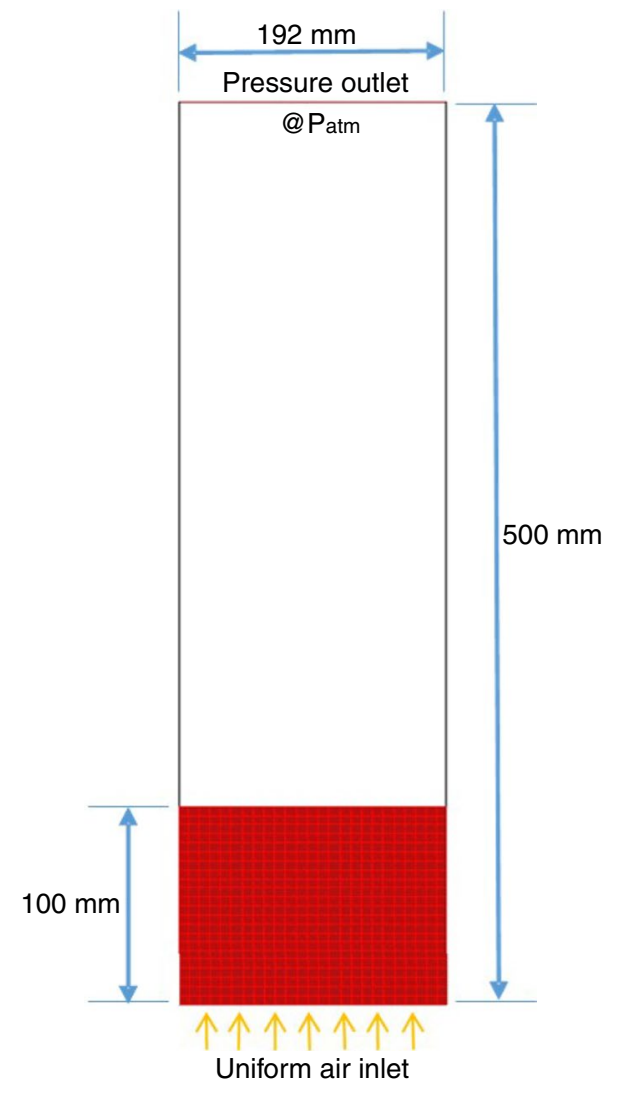

Figure 4 The bed geometry and the boundary conditions used in the present study

\section{Non-spherical SRF particles system}

The typical sphericity of SRF was not measured because such material is heterogeneous in density, size, and shape. For simplicity, we assumed SRF as mono-sized, monodensity, and mono-sphericity particles in the CFD simulations. The mass-weighted average size was estimated from the SRF cumulative size distribution in a previous publication [41]. A validation test is carried out to find out the optimum overall sphericity ratio of SRF particles. In all simulation cases, computations are executed for a total time period of 30 seconds with time-averaging over the last 10 seconds.

Figure 6 presents results of implementing particles' sphericity ratio on numerical predictions. It can be clearly noticed that SRF particles should not be treated as spherical particles and the optimum overall sphericity ratio of SRF particles which can give the best prediction results is within the range of 0.123-0.23 (see Fig. 6a). But there is a large SRF particle entrainment in case of decreasing sphericity below 0.23 (See Fig. 7). Also, the Syamlal-O'Brien drag model with modified drag coefficient gives poor predictions as it overpredicts drag force and a high-SRF particles entrainment occurs as a result (see Fig. 7d). Treating SRF as spherical particles results in homogeneous distribution of SRF particles over the fluidized bed domain as shown in Fig. 7. Increasing the drag force due to low particles' sphericity results in accumulation of SRF particles in high concentration spots near bed walls. At very low sphericity ratio $<0.23$, the drag force is high enough to entrain the particles outside the column.

\section{SRF mixing in a bubbling bed}

A comparison between CFD model predictions and the experimental data of flotsam relative mass fraction at different axial zones within the bed (bottom, middle, and top) with variation of dimensionless fluidization velocity is shown in Fig. 8. The data show a decreasing trend of SRF concentration at bed bottom and bed top at lower fluidization velocity ratios ( $\mathrm{ur}<1.6$ ), while SRF concentration increases from 0.10 to 0.34 at bed body (middle). At elevated fluidization velocities ( $u r=1.6-2.0$ ), $S R F$ concentration rises at top layer and continues decreasing at bottom layer with a smaller decreasing rate. On the other hand, SRF concentration reaches a saturation state and stabilizes around a constant value of $34 \%$. The experimental results show closer ratios of SRF content within bed bottom, middle, and top in the range of $20-40 \%$ at smaller fluidization velocities (ur $<1.5$ ). Above this velocity (ur $>1.5$ ), bottom composition decreases with a quadratic rate and the top layer concentration increases with an inverse trend to that of the bottom

Table 2 A summary of the present model settings and parameters

\begin{tabular}{llll}
\hline Particle viscosity & KTGF & Particle-particle restitution coefficient & $\begin{array}{c}0.9 \text { (sand-sand), 0.7 (sand- } \\
\text { SRF), 0.6 (SRF-SRF) }\end{array}$ \\
Collision viscosity & Gidaspow et al. [14] & Particle-wall restitution coefficient & 0.9 \\
Bulk viscosity & Lun et al. [21] & Gas-wall boundary & No-slip \\
Friction viscosity & Schaeffer [34] & Particle-wall boundary & Partial-slip, specularity factor 0.6 \\
Angle of friction & $30^{\circ}$ & Convergence criteria & $1 \mathrm{e}-3$ \\
Max. friction packing & 0.61 & Max. Iter/time step & 50 \\
Granular temperature model & Algebraic & Time step & $0.001 \mathrm{~s}$ \\
Max. packing & 0.63 & Total simulation time & $30 \mathrm{~s}$ \\
\hline
\end{tabular}



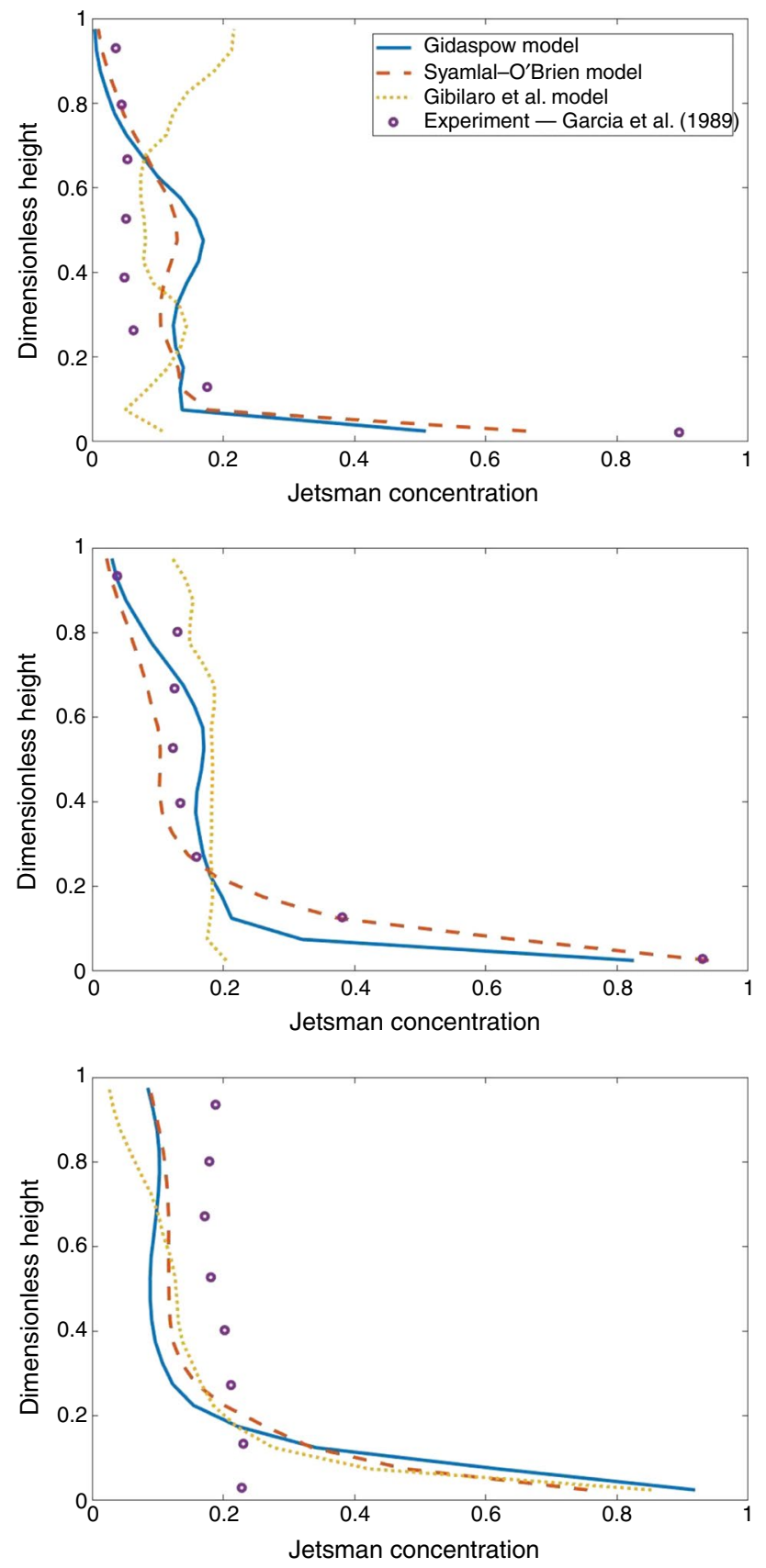

Figure 5 Jetsam concentration prediction using different gas-solid drag models in comparison with experimental data of Geldart D binary systems

layer. This is clearly shown by SRF velocity vectors where motion of particles is observed of overall migration from bottom to top layer. The CFD predictions are carried out on sand of medium jetsam particle size $\left(d_{\mathrm{p}}=810 \mu \mathrm{m}\right)$ and flotsam SRF particles of equivalent spherical mean diameter $\left(d_{\mathrm{p}}=3520 \mu \mathrm{m}\right)$. Two CFD solutions are presented in this figure: the first one is considering SRF as spherical particles (i.e., sphericity ratio $=1.00$ ), while the other solution
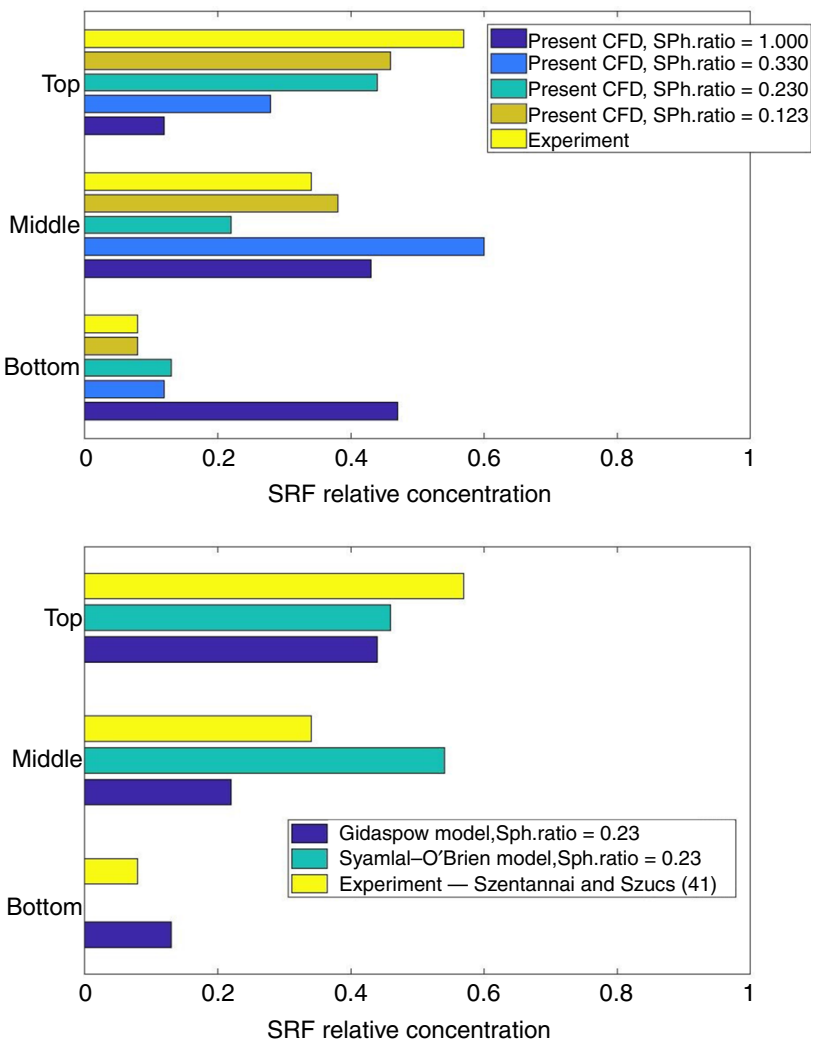

Figure 6 Effect of SRF particles' sphericity ratio on CFD predictions in comparison with experimental data from the literature (fluidization velocity ratio $=2.0, d_{\mathrm{p}}=810 \mu \mathrm{m}$ )

includes using UDF for modifying drag coefficient (i.e., SRF particles of sphericity $=0.23$ ) [49]. It can be clearly noticed from Fig. 8 that the CFD model which uses modified drag coefficient gives overall acceptable agreement with the experimental data. The lower sphericity ratio solution predicts the same concaving curve of the experimental data of SRF relative concentration at bed top as well as the convex shape curve of SRF relative concentration at bed body (middle). The CFD model of higher sphericity ratio gives better result in bed bottom regime at low fluidization velocity ratios (ur $<1.5$ ), while over this range the lower sphericity solution is in good agreement with the experimental data. The figure shows also that the CFD model using spherical SRF particles (i.e., sphericity ratio $=1.00$ ) cannot be reliable and gives overall poor prediction results.

The bed material (sand) particles' mean size is an important parameter in fluidization process. Thus, we tested three sand samples of three different mean sizes $(654 \mu \mathrm{m}, 810 \mu \mathrm{m}$, and $1110 \mu \mathrm{m})$. Figure 9 shows a comparison between SRF relative mass fractions at a moderate fluidization velocity in three bed locations: bottom, middle, and top using different particles' sizes. The experimental results show a significant influence of bed material on SRF concentration within the bed. The biggest 

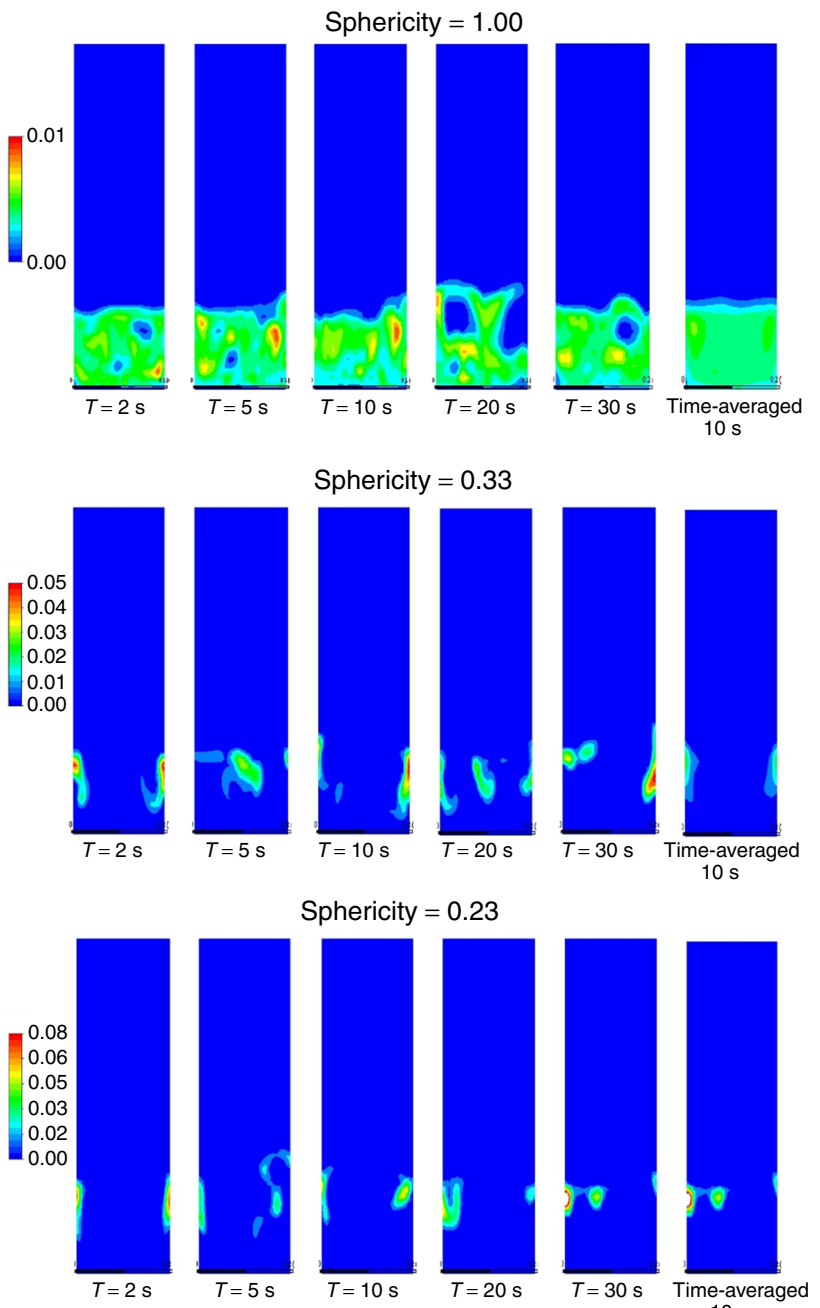

Sphericity $=0.23$
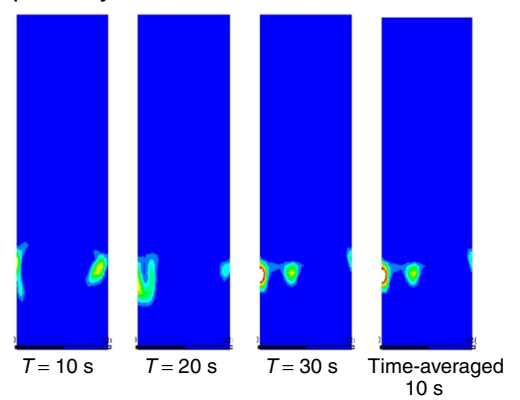

Sphericity $=0.123$
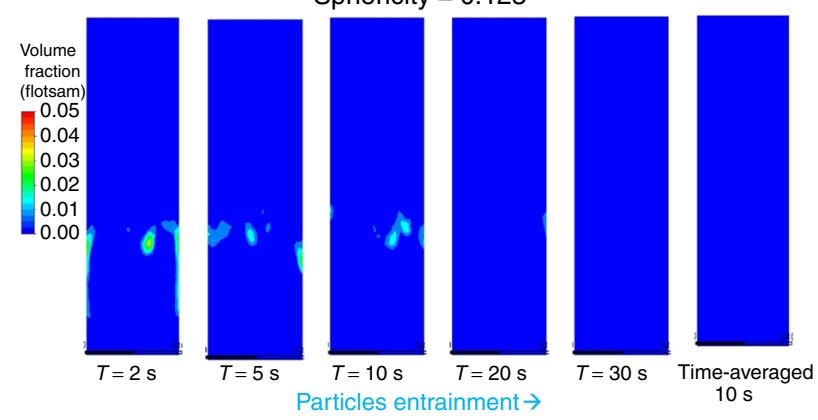

Figure 7 Effect of particles sphericity ratio on SRF void fraction contours in a bubbling bed (ur $\left.=1.6, d_{\mathrm{p}}=810 \mu \mathrm{m}\right)$

mean-size bed $\left(d_{\mathrm{pm}}=1110 \mu \mathrm{m}\right)$ has the highest segregation behavior, where SRF concentration is minimum at bed bottom and maximum in bed middle. The opposite trend occurs in the smallest bed of mean size $\left(d_{\mathrm{pm}}=654 \mu \mathrm{m}\right)$. The present model gives overall acceptable predictions with the experimental data.
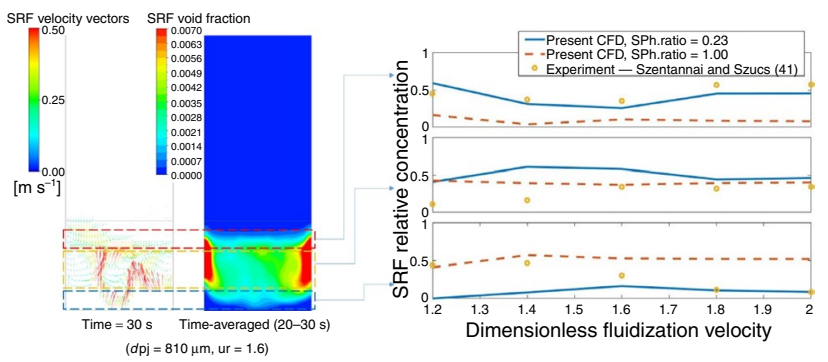

Figure 8 Flotsam velocity vectors and relative mass fraction at three different bed axial regimes (bottom, middle, and top)

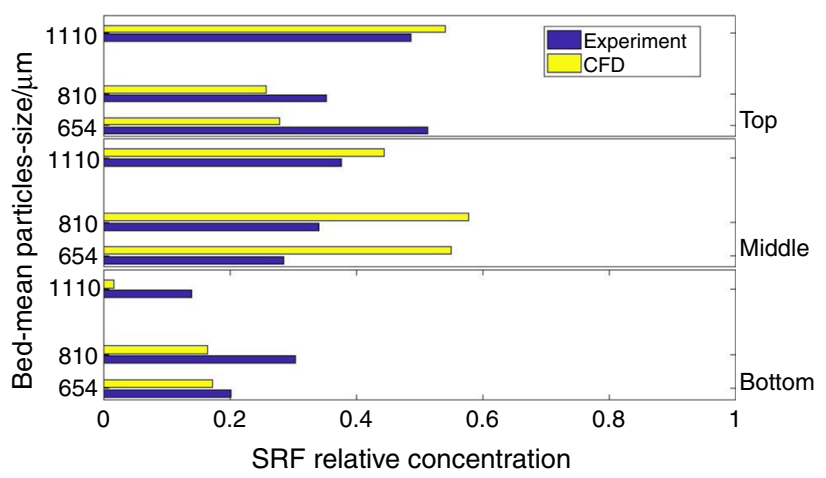

Figure 9 Comparison between SRF relative mass fraction at different axial bed locations (bottom, middle, and top) at fluidization velocity ratio, ur $=1.6$ and using different bed material sizes

\section{Thermal field analysis}

Heat transfer is one of the greatest advantages of fluidized bed due to high thermal exchange potential among fluidization gas and solid bed material. Generally, in fluidized bed applications, the solid bed material is of high thermal conductivity (low conductive resistance) which makes the overall heat transfer coefficient simply independent of solid particles material. The most widely used closure for gas-solid heat transfer is the Gunn's correlation [16] which is valid for voidage $>0.35$ and Reynolds number up to $10^{5}$. The Gunn's correlation is given as follows:

$$
\begin{aligned}
N u= & \frac{h_{\mathrm{gs}} d_{\mathrm{p}}}{\lambda_{\mathrm{g}}}=\left(1-10 \varepsilon_{\mathrm{g}}+5 \varepsilon_{\mathrm{g}}{ }^{2}\right)\left(1+0.7 \operatorname{Re}_{\mathrm{p}}{ }^{2} \operatorname{Pr}^{\frac{1}{3}}\right) \\
& +\left(1.33-2.4 \varepsilon_{\mathrm{g}}+1.2 \varepsilon_{\mathrm{g}}{ }^{2}\right) \operatorname{Re}_{\mathrm{p}}^{0.7} \operatorname{Pr}^{\frac{1}{3}}
\end{aligned}
$$

where Prandtl number is defined as $\operatorname{Pr}=\mu_{\mathrm{g}} C_{\mathrm{p}_{\mathrm{g}}} / \lambda_{\mathrm{g}}$ and $C_{\mathrm{p}_{\mathrm{g}}}$ is the specific heat of the gas phase.

Thermal model validation is important part before performing any numerical investigations. Thus, we used two different experimental cases from the literature representing wall-bed and gas-solid heat transfer mechanisms. Table 3 
Table 3 Thermo-physical properties of the experimental validation cases from the literature

\begin{tabular}{lllllll}
\hline & \multicolumn{2}{l}{ Yusuf et al. } & & \multicolumn{2}{l}{ Simsek et al. } \\
& {$[48]$} & & & {$[37]$} & \\
\cline { 2 - 3 } \cline { 6 - 7 } Property & Gas & Solids & & Gas & Solids \\
\hline Diameter $/ \mu \mathrm{m}$ & - & 491 & & - & 12600 \\
Density $/ \mathrm{kg} \mathrm{m}^{-3}$ & 1.2 & 2485 & & 1.205 & 1440 \\
Viscosity $/ \mathrm{Pas}$ & $1.8 \mathrm{e}-5$ & - & & $1.82 \mathrm{e}-5$ & - \\
Specific heat $/ \mathrm{J} \mathrm{kg}^{-1} \mathrm{~K}^{-1}$ & 994 & 737 & & 1005 & 1350 \\
Thermal conductivity $/ \mathrm{W} \mathrm{m}^{-1} \mathrm{~K}^{-1}$ & 0.026 & 1.0 & & 0.0243 & 0.16 \\
\hline
\end{tabular}

shows the conditions of the two exciting experimental systems.

Figure 10 shows a comparison between present thermal model predictions and experimental data from the literature of gas-solid and wall-bed heat transfer. This figure demonstrates that the macroscopic wall-bed heat transfer phenomenon can be well predicted by using the present MFM model. However, this MFM cannot predict correctly the mesoscopic gas-solid heat transfer and a higher-resolution simulation approach is needed such as the discrete element model (DEM) which gives good agreement with the experimental data. Based on this validation, we limit the numerical study to investigate wall-bed heat transfer of SRF-sand binary system.
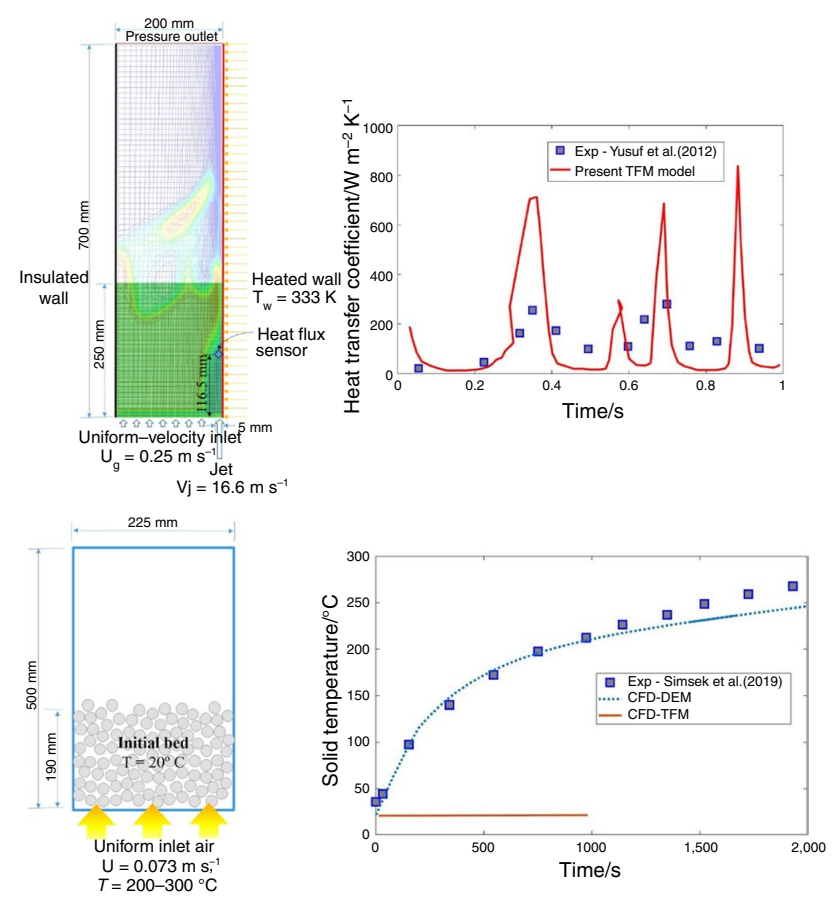

Figure 10 Thermal model validation with experimental cases from the literature

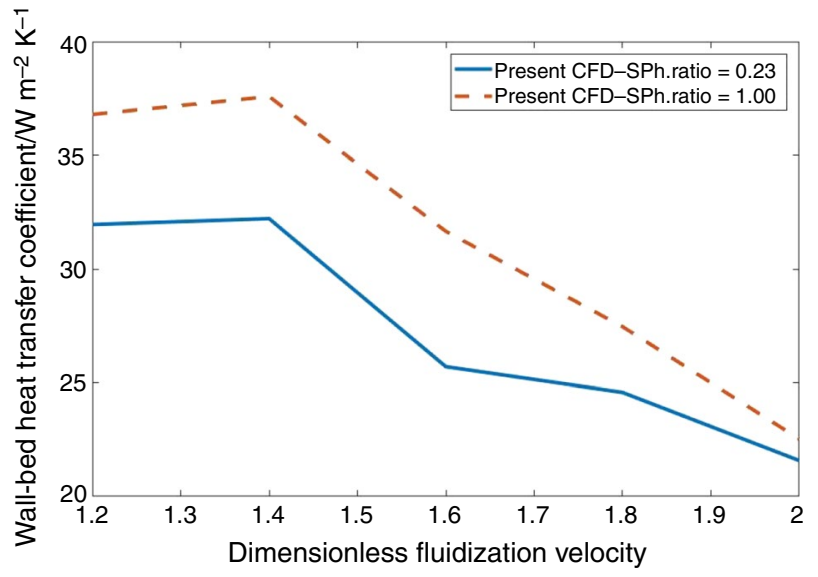

Figure 11 Effect of SRF sphericity ratio on wall-bed heat transfer coefficient predictions

No studies in the literature have concerned with studying effect of particles sphericity on heat transfer coefficient in bubbling beds. Thus, we extended the numerical study to include this important aspect. In order to study the thermal field, we assumed air enters the bed with a temperature of $27^{\circ} \mathrm{C}$ and heat is supplied from the side walls $(T=$ $127^{\circ} \mathrm{C}$ ). Accordingly, simulations were extended for another 10 seconds and the resultant wall-bed heat transfer coefficient is recorded for each fluidization velocity. Figure 11 shows a comparison among model heat transfer coefficient predictions using different SRF sphericity ratios. It is clear from this figure that the wall-bed heat transfer coefficient decreases with increasing fluidization velocity. Also, heat transfer results predicted using low sphericity model is lower than that of the default spherical drag model.

\section{Conclusions}

Simulation of mixing and segregation in binary fluidized beds is a challenging problem, especially when it comes to heterogeneous material like SRF. In this study, Eulerian-Eulerian multi-fluid model was set up to simulate mixing behavior of large SRF particles in a bubbling fluidized bed. SRF of irregular-shaped Geldart D particles was modeled numerically in a binary mixture with Geldart B sand particles. The experimental data included the effect of the fluidization velocity ratio and effect of bed particles' sizes on the SRF relative concentration. The results concluded that SRF particles cannot be simulated as spherical particles, while assuming them as disks of overall sphericity ratio of 0.23 can give acceptable agreement with experimental data. The fluidization velocity has a significant influence on mixing of SRF particles. SRF concentration was found decreasing at bed bottom and bed top layers at low 
fluidization velocities $\left(u / u_{\mathrm{mf}}<1.6\right)$, while increasing at bed body (middle layer). At elevated velocities $\left(u / u_{\mathrm{mf}}>1.6\right)$, SRF concentration in top layer was increasing, and decreasing with same rate from bottom layer. The biggest meansize bed material $\left(d_{\mathrm{pm}}=1110 \mu \mathrm{m}\right)$ was found of the highest segregation behavior.

Regarding the thermal field, the present model was validated by experimental data from the literature of wall-bed and gas-solid heat transfer. The model showed good agreement with wall-bed experimental heat transfer data from the literature. Finally, wall-bed heat transfer coefficient decreased with increasing fluidization velocity.

Acknowledgements Open access funding provided by Budapest University of Technology and Economics (BME). This work was supported by the National Research, Development and Innovation Fund of Hungary in the frame of FIEK 16-1-2016-0007 (Higher Education and Industrial Cooperation Center) project and the ÚNKP-19-3-I-BME-270 New National Excellence Program of the Ministry for Innovation and Technology.

Open Access This article is licensed under a Creative Commons Attribution 4.0 International License, which permits use, sharing, adaptation, distribution and reproduction in any medium or format, as long as you give appropriate credit to the original author(s) and the source, provide a link to the Creative Commons licence, and indicate if changes were made. The images or other third party material in this article are included in the article's Creative Commons licence, unless indicated otherwise in a credit line to the material. If material is not included in the article's Creative Commons licence and your intended use is not permitted by statutory regulation or exceeds the permitted use, you will need to obtain permission directly from the copyright holder. To view a copy of this licence, visit http://creativecommons.org/licenses/by/4.0/.

\section{References}

1. ANSYS FLUENT Theory Guide; SAS IP, Inc; 2016.

2. Armstrong L, Luo K, Gu S. Two-dimensional and three-dimensional computational studies of hydrodynamics in the transition from bubbling to circulating fluidised bed. Chem Eng J. 2010;160(1):239-48. https://doi.org/10.1016/j.cej.2010.02.032.

3. Azimi E, Karimipour S, Nikrityuk P, Szymanski J, Gupta R. Numerical simulation of 3-phase fluidized bed particle segregation. Fuel. 2015;150:347-59. https://doi.org/10.1016/j. fuel.2015.02.042.

4. Begum S, Rasul M, Akbar D, Cork D. An experimental and numerical investigation of fluidized bed gasification of solid waste. Energies. 2013;7(1):43-61. https://doi.org/10.3390/en701 0043.

5. Cardoso J, Silva V, Eusébio D, Brito P. Hydrodynamic modelling of municipal solid waste residues in a pilot scale fluidized bed reactor. Energies. 2017;10(11):1773. https://doi.org/10.3390/ en10111773.

6. Chao Z, Wang Y, Jakobsen JP, Fernandino M, Jakobsen HA. Multi-fluid modeling of density segregation in a dense binary fluidized bed. Particuology. 2012;10(1):62-71. https://doi. org/10.1016/j.partic.2011.10.001.

7. Cho J, Kim Y, Song J, Lee TK, Song HH. Design of dynamic plant model and model-based controller for a heat recovery system with a swirling flow incinerator. Energy. 2018;147:1016-29. https:// doi.org/10.1016/j.energy.2017.12.001.

8. Dioguardi F, Mele D, Dellino P. A new one-equation model of fluid drag for irregularly shaped particles valid over a wide range of Reynolds number. J Geophys Res Solid Earth. 2018;123(1):144-56. https://doi.org/10.1002/2017JB014926.

9. Formisani B, Cristofaro G, Girimonte R. A fundamental approach to the phenomenology of fluidization of size segregating binary mixtures of solids. Chem Eng Sci. 2001;56(1):109-19. https://doi. org/10.1016/S0009-2509(00)00426-7.

10. Formisani B, Girimonte R, Longo T. The fluidization pattern of density-segregating binary mixtures. Chem Eng Res Des. 2008;86(4):344-8. https://doi.org/10.1016/j.cherd.2007.11.004.

11. Geldart D. Types of gas fluidization. Powder Technol. 1973;7:285-92.

12. Gibilaro L, Di Felice R, Waldram S, Foscolo P. Generalized friction factor and drag coefficient correlations for fluid-particle interactions. Chem Eng Sci. 1985;40(10):1817-23.

13. Gidaspow D. Multiphase flow and fluidization: continuum and kinetic theory descriptions. Boston: Academic Press; 1994.

14. Gidaspow D, Bezburuah R, Ding J. Hydrodynamics of circulating fluidized beds, kinetic theory approach. In: Proceedings of the 7th engineering foundation conference on fluidization, 1992. p. 75:821992.

15. Guan Y, Guadarrama-Lara R, Jia X, Zhang K, Wen D. Lattice Boltzmann simulation of flow past a non-spherical particle. Adv Powder Technol. 2017; https://doi.org/10.1016/j. apt.2017.03.018.

16. Gunn DJ. Transfer of heat or mass to particles in fixed and fluidized beds. Int J Heat Mass Transf. 1978;21:467-76. https://doi. org/10.1016/0017-9310(78)90080-7.

17. Haider A, Levenspiel O. Drag coefficient and terminal velocity of spherical and nonspherical particles. Powder Technol. 1989;58(1):63-70. https://doi.org/10.1016/0032-5910(89)80008 $-7$.

18. He L, Tafti DK. Heat transfer in an assembly of ellipsoidal particles at low to moderate Reynolds numbers. Int J Heat Mass Transf. 2017;114:324-36. https://doi.org/10.1016/j.ijheatmass transfer.2017.06.068.

19. Hwang JG, Choi HS, Kwon JH. The mixing and segregation characteristics of rice straw in a cylindrical bubbling fluidized bed. J Mater Cycles Waste Manag. 2016;18(4):771-80. https://doi. org/10.1007/s10163-015-0384-9.

20. Kumar R, Singh RI. An investigation of co-combustion municipal sewage sludge with biomass in a $20 \mathrm{~kW}$ BFB combustor under airfired and oxygen-enriched condition. Waste Manag. 2017;70:114 26. https://doi.org/10.1016/j.wasman.2017.09.005.

21. Lun CKK, Savage SB, Jeffrey DJ, Chepurniy N. Kinetic theories for granular flow: Inelastic particles in Couette flow and slightly inelastic particles in a general flowfield. J Fluid Mech. 1984;140(1):223-56. https://doi.org/10.1017/S00221120840005 86.

22. Mätzing H, Gehrmann HJ, Seifert H, Stapf D. Modelling grate combustion of biomass and low rank fuels with CFD application. Waste Manag. 2018;78:686-97. https://doi.org/10.1016/j.wasma n.2018.05.008.

23. Moradian F, Pettersson A, Svärd S, Richards T. Co-combustion of animal waste in a commercial waste-to-energy BFB boiler. Energies. 2013;6(12):6170-87. https://doi.org/10.3390/en6126170.

24. Násner AML, Lora EES, Palacio JCE, Rocha MH, Restrepo JC, Venturini OJ, Ratner A. Refuse derived fuel (RDF) production and gasification in a pilot plant integrated with an Otto cycle ICE through Aspen plus ${ }^{\mathrm{TM}}$ modelling: thermodynamic and economic viability. Waste Manag. 2017;69:187-201. https://doi. org/10.1016/j.wasman.2017.08.006. 
25. Nasserzadeh V, Swithenbank J, Schofield C, Scott D, Loader A, Leonard A, Russell R, Winn D. Three-dimensional modelling of the Coventry MSW incinerator using computational fluid dynamics and experimental data. Process Saf Environ Prot Trans Inst Chem Eng Part B. 1993;71:269-79.

26. Nienow A, Naimer N, Chiba T. Studies of segregation/mixing in fluidised beds of different size particles. Chem Eng Commun. 1987;62:53-66. https://doi.org/10.1080/00986448708912050.

27. Oka S, Anthony EJ. Fluidized bed combustion. No. 162 in mechanical engineering. New York: M. Dekker; 2004.

28. Palappan KG, Sai P. Studies on segregation of binary mixture of solids in a continuous fast fluidized bed. Chem Eng J. 2008;138(1-3):358-66. https://doi.org/10.1016/j.cej.2007.08.003.

29. Park HC, Choi HS. The segregation characteristics of char in a fluidized bed with varying column shapes. Powder Technol. 2013;246:561-71. https://doi.org/10.1016/j.powtec.2013.06.019.

30. Qin K, Thunman H, Leckner B. Mass transfer under segregation conditions in fluidized beds. Fuel. 2017;195:105-12.

31. Recari J, Berrueco C, Puy N, Alier S, Bartrolí J, Farriol X. Torrefaction of a solid recovered fuel (SRF) to improve the fuel properties for gasification processes. Appl Energy. 2017;203:177-88. https://doi.org/10.1016/j.apenergy.2017.06.014.

32. Rowe P, Nienow A. Particle mixing and segregation in gas fluidised beds. A review. Powder Technol. 1976;15(2):141-7. https:// doi.org/10.1016/0032-5910(76)80042-3.

33. Salatino P, Solimene R. Mixing and segregation in fluidized bed thermochemical conversion of biomass. Powder Technol. 2017;316:29-40. https://doi.org/10.1016/j.powtec.2016.11.058.

34. Schaeffer DG. Instability in the evolution equations describing incompressible granular flow. J Differ Equ. 1987;66(1):19-50. https://doi.org/10.1016/0022-0396(87)90038-6.

35. Schiller L, Naumann L. A drag coefficient correlation. Z Ver Deutsch Ing. 1935;77(1):318-20.

36. Silva JE, Calixto GQ, de Almeida CC, Melo DMA, Melo MAF, Freitas JCO, Braga RM. Energy potential and thermogravimetric study of pyrolysis kinetics of biomass wastes. J Therm Anal Calorim. 2019;137:1635-43. https://doi.org/10.1007/s10973-01908048-4.

37. Simsek E, Brosch B, Wirtz S, Scherer V, Krüll F. Numerical simulation of grate firing systems using a coupled CFD/discrete element method (DEM). Powder Technol. 2009;193(3):266-73. https://doi.org/10.1016/j.powtec.2009.03.011.

38. Skorek-Osikowska A, Kotowicz J, Uchman W. Thermodynamic assessment of the operation of a self-sufficient, biomass based district heating system integrated with a Stirling engine and biomass gasification. Energy. 2017;141:1764-78. https://doi.org/10.1016/j. energy.2017.11.106.

39. Sun R, Ismail TM, Ren X, El-Salam MA. Influence of simulated MSW sizes on the combustion process in a fixed bed: CFD and experimental approaches. Waste Manag. 2016;49:272-86. https ://doi.org/10.1016/j.wasman.2015.12.019.
40. Syamlal M, O'Brien T. Computer simulation of bubbles in a fluidized bed. AIChE Symp Ser. 1989;85:22-31.

41. Szentannai P, Szücs B. Vertical arrangement of SRF particles in a stationary fluidized bed. Powder Technol. 2018;325:209-17. https ://doi.org/10.1016/j.powtec.2017.11.015.

42. Szücs B, Szentannai P. Experimental investigation on mixing and segregation behavior of oxygen carrier and biomass particle in fluidized bed. Period Polytech Mech Eng. 2019;63(3):188-94. https://doi.org/10.3311/PPme.13764.

43. Szücs T, Szentannai P, Szilágyi IM, Bakos LP. Comparing different reaction models for combustion kinetics of solid recovered fuel. J Therm Anal Calorim. 2019;. https://doi.org/10.1007/s1097 3-019-08438-8.

44. Xia Z, Li J, Wu T, Chen C, Zhang X. CFD simulation of MSW combustion and SNCR in a commercial incinerator. Waste Manag. 2014;34(9):1609-18.

45. Xiaodong L. Study on mixing performance of municipal solid waste (MSW) in differential density fluidized beds (FBs). Chem Eng J. 2001;84(2):161-6. https://doi.org/10.1016/S1385 -8947(01)00200-5.

46. Yang J, Wang Q, Zeng M, Nakayama A. Computational study of forced convective heat transfer in structured packed beds with spherical or ellipsoidal particles. Chem Eng Sci. 2010;65(2):72638. https://doi.org/10.1016/j.ces.2009.09.026.

47. Yunos NFM, Najmi NH, Munusamy SRR, Idris MA. Effect of high temperature on reduction-controlling reaction rate of agricultural waste chars and coke with steelmaking slag. J Therm Anal Calorim. 2019;138:175-83. https://doi.org/10.1007/s1097 3-019-08221-9.

48. Yusuf R, Halvorsen B, Melaaen MC. An experimental and computational study of wall to bed heat transfer in a bubbling gassolid fluidized bed. Int J Multiph Flow. 2012;42:9-23. https://doi. org/10.1016/j.ijmultiphaseflow.2012.01.003.

49. Zhang Y, Zhao Y, Lu L, Ge W, Wang J, Duan C. Assessment of polydisperse drag models for the size segregation in a bubbling fluidized bed using discrete particle method. Chem Eng Sci. 2017;160:106-12. https://doi.org/10.1016/j.ces.2016.11.028.

50. Zhong W, Yu A, Liu X, Tong Z, Zhang H. DEM/CFD-DEM modelling of non-spherical particulate systems: theoretical developments and applications. Powder Technol. 2016;302:108-52. https ://doi.org/10.1016/j.powtec.2016.07.010.

51. Zhou Q, Wang J. CFD study of mixing and segregation in CFB risers: extension of EMMS drag model to binary gas-solid flow. Chem Eng Sci. 2015;122:637-51. https://doi.org/10.1016\%2Fj. ces.2014.10.025.

Publisher's Note Springer Nature remains neutral with regard to jurisdictional claims in published maps and institutional affiliations. 